\title{
MicroRNA-7 Is Associated with Malignant Potential and Poor Prognosis in Human Colorectal Cancer
}

\author{
YUKA NAGANO $^{1}$, YUJI TOIYAMA ${ }^{1}$, YOSHINAGA OKUGAWA ${ }^{1}$, HIROKI IMAOKA ${ }^{1}$, HIROYUKI FUJIKAWA ${ }^{1}$, \\ HIROMI YASUDA $^{1}$, SHIGEYUKI YOSHIYAMA ${ }^{1}$, JUNICHIRO HIRO ${ }^{1}$, MINAKO KOBAYASHI ${ }^{2}$, MASAKI OHI ${ }^{1}$, \\ TOSHIMITSU ARAKI ${ }^{1}$, YASUHIRO INOUE ${ }^{1}$, YASUHIKO MOHRI ${ }^{1}$ and MASATO KUSUNOKI ${ }^{1}$ \\ ${ }^{1}$ Department of Gastrointestinal and Pediatric Surgery, Division of Reparative Medicine, Institute of Life Sciences, \\ and ${ }^{2}$ Department of Innovative Surgery, Mie University Graduate School of Medicine, Mie, Japan
}

\begin{abstract}
Dysregulation pattern of microRNA-7 (miR-7) and the clinical significance of its expression in colorectal cancer (CRC) are unresolved. Here, we investigated the relationship between clinicopathological factors, including prognostic outcome, and miR-7 expression in CRC tissues. We analyzed miR-7 expression levels by real-time reverse transcription polymerase chain reaction in 210 colorectal tissues (196 CRCs and 14 normal mucosae from healthy volunteers). miR-7 expression levels were significantly upregulated in CRC tissues compared to normal colorectal mucosae. Elevated miR-7 expression was significantly correlated with tumour depth, venous invasion, lymphatic invasion, lymph node metastasis, and liver metastasis. High miR-7 expression was significantly associated with poor overall survival in patients with $C R C(p=0.010)$. Moreover, miR-7 expression was an independent prognostic factor in patients with CRC (hazard ratio $=1.854,95 \%$ confidence interval $=1.016-3.540 ; p=0.044)$. $m i R-7$ acts as an oncogene in CRC and is significantly associated with tumour progression and poor prognosis.
\end{abstract}

Colorectal cancer (CRC) is a leading cause of cancer deaths worldwide (1). Over 1.3 million new cases of CRC are diagnosed every year, and almost 700,000 CRC deaths occurred in $2012(1,2)$. Although CRC is curable if diagnosed at an early stage of tumour development, approximately half of all patients with advanced CRC experience local recurrence or distant metastasis, and disease prognosis remains poor $(3,4)$. Accordingly, there is an urgent

Correspondence to: Yuji Toiyama, Department of Gastrointestinal and Pediatric Surgery, Division of Reparative Medicine, Institute of Life Sciences, Mie University Graduate School of Medicine, 2-174 Edobashi, Tsu, Mie 514-8507, Japan. Tel: +81 592315294, Fax: +81 592326968, e-mail: ytoi0725@clin.medic.mie-u.ac.jp

Key Words: miR-7, colorectal cancer, poor prognosis. need for the development of biomarkers that can identify high-risk patients who require an intensive treatment protocol to improve their prognosis.

MicroRNAs (miRNAs) are endogenous, evolutionarily conserved, naturally abundant, relatively stable, small (1825 nucleotides) non-coding RNAs that regulate gene expression by inhibiting or inactivating target messenger RNAs (mRNAs) (5-8). miRNAs play a crucial role in the regulation of various processes related to development and other physiological functions, consequently their dysregulation causes a range of diseases, including malignancies (9). In CRC, miR-135a/b and miR-122a directly inactivate the adenomatous polyposis coli tumoursuppressor gene (10). The miR-200 family represses epithelial-to-mesenchymal transition by targeting zinc finger E-box-binding homeobox 1 (ZEB1) and ZEB2, which downregulate E-cadherin and up-regulate vimentin; these are involved in CRC metastasis (10). Additionally, miR-21 is significantly up-regulated in metastatic CRC and silences the tumour-suppressor genes programmed cell death 4 and transforming growth factor- $\beta$ receptor 2 , with a concomitant decrease in $\beta$-catenin expression (10). Although miR-7 has been reported to be an onco-suppressive miRNA in various types of cancer, such as melanoma (11) and breast cancer (12), its dysregulation pattern in CRC is controversial (13), and its biomarker potential uncertain.

The aim of this study, was therefore, to investigate the association between clinicopathological factors, including prognostic outcome, and miR-7 expression in CRC tissues, and to clarify the clinical feasibility of using $m i R-7$ to predict prognosis of patients with CRC.

\section{Materials and Methods}

Patients, study design, and clinical specimens. A total of 210 tissue specimens were examined including 196 formalin-fixed paraffinembedded (FFPE) primary CRC tissues and 14 normal mucosa tissues from healthy volunteers. Patients with CRC underwent 
surgery at our Institution between January 2005 and December 2010. Patients with inflammatory conditions including infectious or collagen diseases were excluded. No patient had received chemotherapy or radiation therapy prior to surgery, and no perioperative mortalities were observed. The diagnosis of CRC was confirmed for all 196 patients based on clinicopathological findings. The locations of tumours and distant metastases were determined by barium enema, colonoscopy, computed tomography (CT), and magnetic resonance imaging. Patients with stage III and IV disease received fluorouracil-based chemotherapy, whereas no adjuvant therapy was given to patients with stage I and II disease.

Patients were observed at 3-month intervals for 24 months after surgery, then every 6 months for 3 years, and then on an annual basis. A medical history was taken and a physical examination was performed at each visit, and chest X-ray, colonoscopy, and CT were performed annually. The median follow-up time was 41.3 months (mean $\pm \mathrm{SD}=46.6 \pm 36.5$ months). Among the 196 patients evaluated, 41 died of primary or recurrent disease. The prognostic values of the following clinicopathological parameters were evaluated: tumour location, pathological $\mathrm{T}$ classification, histological type, venous invasion, lymphatic invasion, lymph node metastasis, liver metastasis, distant metastasis, and Union for International Cancer Control (UICC) stage. The obtained tissues were preserved as FFPE tissue samples until use. We obtained written informed consent and willingness to donate their tissue for research from all participants. This study was approved by the Institutional Review Board of Mie University (no. 2643).

Total RNA isolation and quantitative real-time reverse transcription $(q R T)$ polymerase chain reaction $(P C R)$. We extracted total RNA, including miRNA, from FFPE tissue sections using the miRNeasy FFPE Kit (Qiagen, Valencia, CA, USA) according to the manufacturer's protocol. Next, $25 \mathrm{ng}$ small RNAs from FFPE samples were reverse-transcribed using the TaqMan MicroRNA Reverse Transcription Kit (Applied Biosystems, Foster City, CA, USA) according to the manufacturer's instructions. RT products were used as PCR templates, and $m i R-16$ amplification was used to normalise tissue samples. PCR reactions for the quantification of $m i R$ 7 and $m i R$ - 16 were performed using TaqMan Universal PCR Master Mix (Applied Biosystems), and qRT-PCR was carried out using the StepOnePlus real Time PCR System (Applied Biosystems). Cycle threshold $(\mathrm{Ct})$ values were calculated using StepOne Software v2.2.2.

Statistical analysis. Results are expressed as the mean \pm standard deviation (SD). Data were analysed using the JMP 11 software program (SAS Institute, Cary, NC, USA). The Mann-Whitney test evaluated relationships between $m i R-7$ expression and clinicopathological factors. For time-to-event analyses, survival estimates were calculated using the Kaplan-Meier analysis and groups were compared with the log-rank test. Receiver operating characteristic (ROC) curves were established to determine the cutoff values for analysing prognosis by Youden's index. Overall survival was measured from the date the patient underwent surgery until the date of death from any cause (i.e. cancer-unrelated deaths were not censored), or last known follow-up for patients that were still alive. Cox proportional hazards models were used to estimate the hazard ratios for death in patients with CRC. After univariate analysis, variables with $p \leq 0.30$ were selected for multivariate analysis using the Cox proportional hazards regression model. All $p$-values were two-sided, and those less than 0.05 were considered statistically significant.
Table I. Characteristics of patients with colorectal cancer.

\begin{tabular}{|c|c|c|}
\hline Category & Variable & $\begin{array}{c}\text { Number of } \\
\text { patients }\end{array}$ \\
\hline \multirow[t]{2}{*}{ Age* } & $<67$ Years & 95 \\
\hline & $\geq 67$ Years & 101 \\
\hline \multirow[t]{2}{*}{ Gender } & Male & 117 \\
\hline & Female & 79 \\
\hline \multirow[t]{4}{*}{ Location } & Right & 39 \\
\hline & Transverse & 22 \\
\hline & Left & 58 \\
\hline & Rectum & 77 \\
\hline \multirow[t]{5}{*}{ Depth of cancer invasion } & Tis & 8 \\
\hline & $\mathrm{T} 1$ & 25 \\
\hline & $\mathrm{T} 2$ & 26 \\
\hline & $\mathrm{T} 3$ & 87 \\
\hline & $\mathrm{T} 4$ & 50 \\
\hline \multirow[t]{2}{*}{ Histology } & Well/moderately differentiated & 174 \\
\hline & Poorly differentiated & 22 \\
\hline \multirow[t]{2}{*}{ Venous invasion } & Absent & 104 \\
\hline & Present & 92 \\
\hline \multirow[t]{2}{*}{ Lymphatic invasion } & Absent & 150 \\
\hline & Present & 46 \\
\hline \multirow[t]{2}{*}{ Lymph node metastasis } & Absent & 115 \\
\hline & Present & 81 \\
\hline \multirow[t]{2}{*}{ Liver metastasis } & Absent & 165 \\
\hline & Present & 31 \\
\hline \multirow[t]{2}{*}{ Distant metastasis } & Absent & 149 \\
\hline & Present & 47 \\
\hline \multirow[t]{5}{*}{ UICC Stage } & 0 & 3 \\
\hline & I & 42 \\
\hline & II & 59 \\
\hline & III & 45 \\
\hline & IV & 47 \\
\hline
\end{tabular}

UICC: Union for International Cancer Control. *Median age at surgery was 67 years in this cohort.

\section{Results}

Patient characteristics. Patient characteristics are shown in Table I. A total of 117 patients were male and 79 were female. The median age was 67 years. The primary lesion location was in the rectum in 77 patients, the left side colon in 58 patients, the transverse colon in 22 patients, and the right side colon in 39 patients. According to $\mathrm{T}$ classification by UICC, the majority of patients [137/196 (69.9\%)] had T3 or T4 disease. Only 22 patients had poorly differentiated adenocarcinoma. Forty-seven patients had synchronous distant metastases (liver, lung, and peritoneum) at the time of surgery, including 31 with liver metastases.

Overexpression of miR-7 in CRC tissues compared to normal mucosae. miR-7 expression levels were significantly upregulated in CRC tissues compared to normal colorectal mucosae $(p<0.001$, Figure 1). According to clinicopathological stage, there was a tendency for higher $m i R-7$ expression in 


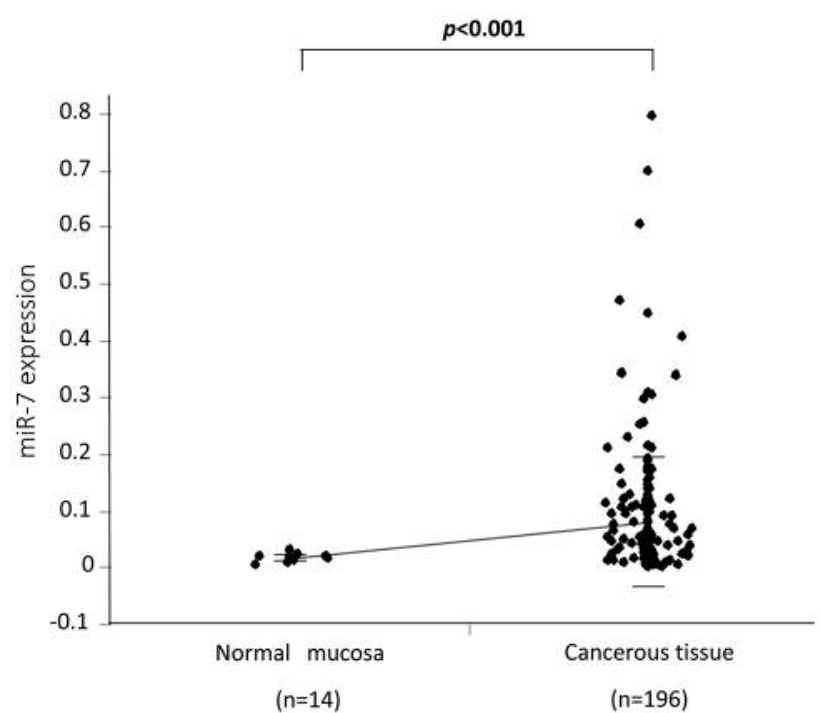

Figure 1. Overexpression of miR-7 in colorectal cancer (CRC) tissues compared to normal colorectal mucosae. miR-7 expression levels were significantly higher in CRC tissues than in normal colorectal mucosae $(p<0.001)$.

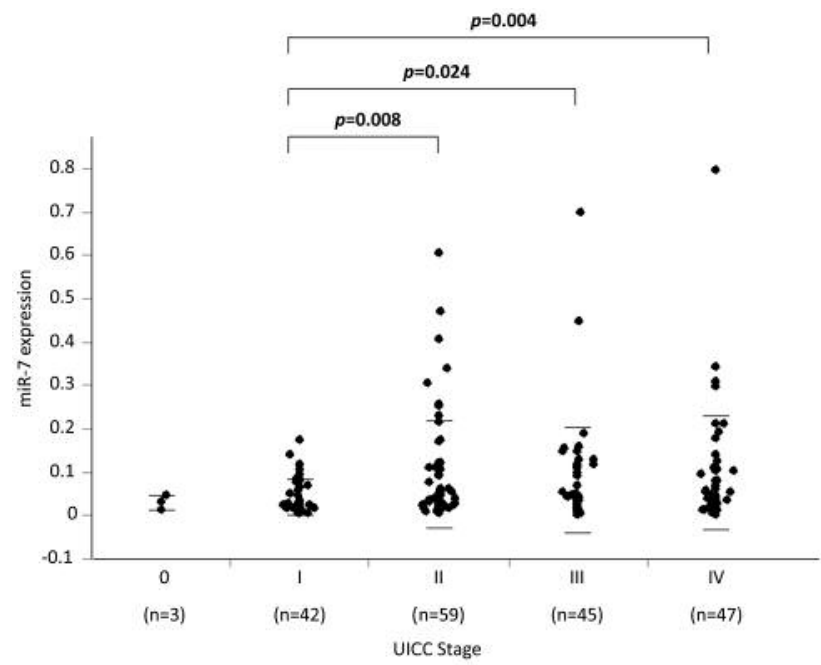

Figure 2. miR-7 expression levels in colorectal cancer (CRC) tissues according to Union for International Cancer Control (UICC) stage. miR-7 tended to be more highly expressed in patients with advanced cancer. miR-7 expression levels in patients with stage II, III, and IV disease were significantly higher than in those with stage I disease $(p=0.008, p=0.024$, and $p=0.004$, respectively).

patients with advanced cancer (Figure 2). In particular, $m i R-7$ expression levels were significantly higher in stage II, III, and IV disease than stage I disease $(p=0.008, p=0.024$, and $p=0.004$, respectively).

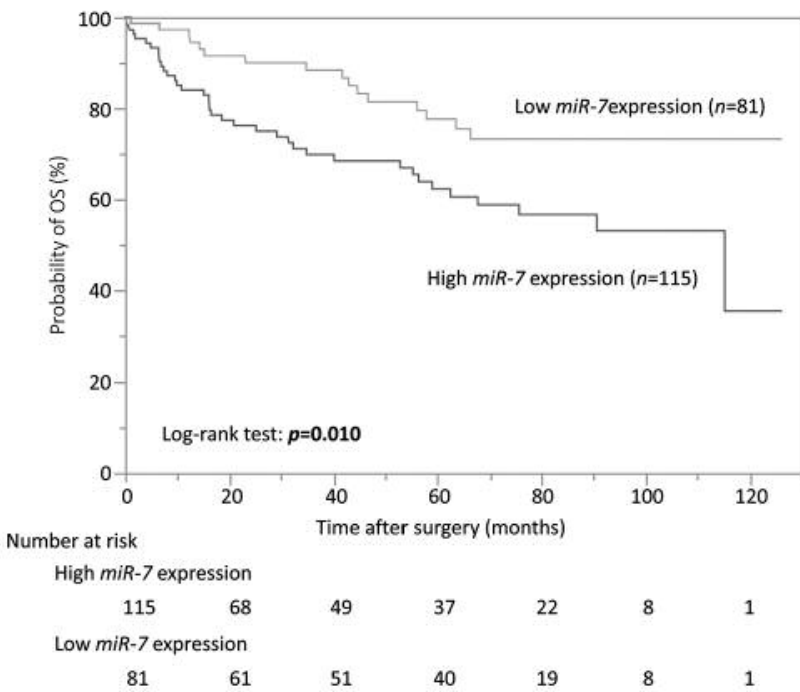

Figure 3. Kaplan-Meier survival analysis of overall survival according to miR-7 expression in colorectal cancer (CRC). High miR-7 expression in CRC tissues was significantly correlated with poor prognosis in patients compared to those with low miR-7 expression (log-rank test $p=0.010$ ).

Correlation between clinicopathological factors and miR-7 expression in CRC. Next, the correlation between clinicopathological factors and $m i R-7$ expression in CRC was investigated (Table II). Interestingly, $m i R$ - 7 overexpression was significantly correlated with factors of disease progression in CRC. Thus, T3 or T4 CRC showed significantly higher miR-7 expression than Tis, T1, or T2 CRC $(p=0.002)$. CRC with venous or lymphatic invasion also expressed significantly higher levels of $m i R-7$ compared with CRC without venous or lymphatic invasion ( $p=0.031$ and $p<0.001$, respectively), while the presence of lymph node metastases or liver metastases was correlated with miR-7 overexpression ( $p=0.010$ and $p<0.001$, respectively). However, $m i R-7$ expression showed no significant relationship with age $(p=0.922)$, gender $(p=0.387)$, location of lesion $(p=0.877)$, histological type $(p=0.079)$, presence of distant metastases $(p=0.109)$, or UICC stage $(p=0.085)$.

High expression of miR-7 in CRC was significantly associated with poor overall survival. The prognostic impact of miR-7 expression in patients with CRC was examined using Kaplan-Meier curve analysis. Interestingly, high levels of miR-7 expression were significantly correlated with poor prognosis compared to low miR-7 expression in this cohort $(p=0.010$, Figure 3$)$.

High expression of miR-7 in CRC was an independent factor of poor overall survival in patients with CRC. Finally, the role of miR-7 expression and clinicopathological factors as predictors of poor prognosis in CRC was evaluated (Table 
Table II. Correlation between clinicopathological factors and miR-7 expression levels in colorectal cancer.

\begin{tabular}{|c|c|c|c|}
\hline Category & Variable & Relative $m i R-7$ expression $($ mean $\pm \mathrm{SD})$ & $p$-Value \\
\hline \multirow[t]{2}{*}{ Age* } & $<67$ Years & $0.088 \pm 0.130$ & 0.922 \\
\hline & $\geq 67$ Years & $0.075 \pm 0.096$ & \\
\hline \multirow[t]{2}{*}{ Gender } & Male & $0.076 \pm 0.120$ & 0.387 \\
\hline & Female & $0.089 \pm 0.103$ & \\
\hline \multirow[t]{2}{*}{ Location } & Right-sided & $0.077 \pm 0.096$ & 0.877 \\
\hline & Left-sided & $0.083 \pm 0.121$ & \\
\hline \multirow[t]{2}{*}{ Depth of cancer invasion } & $\mathrm{T} 0-2$ & $0.050 \pm 0.062$ & 0.002 \\
\hline & $\mathrm{T} 3-4$ & $0.094 \pm 0.127$ & \\
\hline \multirow[t]{2}{*}{ Histology } & Well/moderately differentiated & $0.085 \pm 0.118$ & 0.079 \\
\hline & Poorly differentiated & $0.049 \pm 0.054$ & \\
\hline \multirow[t]{2}{*}{ Venous invasion } & Absent & $0.064 \pm 0.087$ & 0.031 \\
\hline & Present & $0.100 \pm 0.135$ & \\
\hline \multirow[t]{2}{*}{ Lymphatic invasion } & Absent & $0.047 \pm 0.092$ & $<0.001$ \\
\hline & Present & $0.091 \pm 0.118$ & \\
\hline \multirow[t]{2}{*}{ Lymph node metastases } & Absent & $0.069 \pm 0.096$ & 0.010 \\
\hline & Present & $0.098 \pm 0.133$ & \\
\hline \multirow[t]{2}{*}{ Liver metastases } & Absent & $0.073 \pm 0.103$ & $<0.001$ \\
\hline & Present & $0.126 \pm 0.153$ & \\
\hline \multirow[t]{2}{*}{ Distant metastases } & Absent & $0.075 \pm 0.107$ & 0.109 \\
\hline & Present & $0.099 \pm 0.133$ & \\
\hline \multirow[t]{2}{*}{ UICC Stage } & 0 -II & $0.072 \pm 0.100$ & 0.085 \\
\hline & III-IV & $0.091 \pm 0.127$ & \\
\hline
\end{tabular}

UICC: Union for International Cancer Control; SD: standard deviation. *Median age at surgery was 67 years in this cohort. Significant associations are shown in bold $(p<0.05)$.

Table III. Univariate and multivariate analysis for predictors of poor overall survival in patients with colorectal cancer (Cox proportional hazards regression model).

\begin{tabular}{|c|c|c|c|c|c|c|}
\hline \multirow[t]{2}{*}{ Variable } & \multicolumn{3}{|c|}{ Univariate analysis } & \multicolumn{3}{|c|}{ Multivariate analysis } \\
\hline & HR & $95 \% \mathrm{CI}$ & $p$-Value & HR & $95 \% \mathrm{CI}$ & $p$-Value \\
\hline Age $(<67 v s . \geq 67 \text { years })^{*}$ & 1.115 & $0.652-1.935$ & 0.693 & - & - & - \\
\hline Gender (male $v s$. female) & 1.194 & $0.694-2.111$ & 0.526 & - & - & - \\
\hline Location (left sided $v s$. right sided) & 1.604 & $0.871-3.188$ & 0.133 & 1.381 & $0.730-2.806$ & 0.331 \\
\hline Depth of cancer invasion (T3-4 vs. T0-2) & 6.888 & 2.794-22.904 & $<0.001$ & 2.339 & $0.806-8.730$ & 0.125 \\
\hline Histology (poorly $v s$. well/moderately differentiated & 1.636 & $0.746-3.202$ & 0.204 & 1.634 & $0.710-3.424$ & 0.235 \\
\hline Venous invasion (present $v s$. absent) & 3.008 & $1.718-5.484$ & $<0.001$ & 0.872 & $0.452-1.744$ & 0.691 \\
\hline Lymphatic invasion (present $v s$. absent) & 6.227 & $2.290-25.602$ & $<0.001$ & 1.138 & $0.318-5.466$ & 0.853 \\
\hline Lymph node metastasis (present $v s$. absent) & 4.226 & $2.397-7.804$ & $<0.001$ & 2.047 & $1.059-4.152$ & 0.033 \\
\hline Liver metastasis (present $v s$. absent) & 10.004 & $5.659-17.466$ & $<0.001$ & 0.739 & $0.341-1.663$ & 0.455 \\
\hline Distant metastasis (present $v s$. absent) & 15.886 & $8.877-29.363$ & $<0.001$ & 15.200 & $6.220-37.079$ & $<0.001$ \\
\hline UICC Stage (III-IV vs. 0-II) & 6.752 & $3.535-14.243$ & $<0.001$ & - & - & - \\
\hline Tissue $m i R-7$ expression (high $v s$. low) ${ }^{\dagger}$ & 2.124 & $1.205-3.919$ & 0.009 & 1.854 & $1.016-3.540$ & 0.044 \\
\hline
\end{tabular}

UICC: Union for International Cancer Control; HR: hazard ratio; CI: confidence interval. *Median age at surgery was 67 years in this cohort. ${ }^{\dagger}$ Cutoff threshold of miR-7 expression was determined by receiver operating characteristic analysis with Youden's index for overall survival. Significant associations are shown in bold $(p<0.05)$.

III). We identified depth of cancer invasion, venous invasion, lymphatic invasion, lymph node metastasis, liver metastasis, distant metastasis, UICC stage, and tissue $m i R-7$ expression as prognostic factors in $\mathrm{CRC}$ by univariate analysis using the
Cox proportional hazards regression model (all $p<0.001$, except tissue $m i R-7$ expression: $p=0.009$ ). Multivariate analysis of those factors that had values of $p<0.30$ in univariate analysis identified lymph node metastasis, distant 
metastasis, and tissue $m i R-7$ expression as independent predictors of poor overall survival in patients with CRC (hazard ratios $=2.047,15.200$, and $1.854 ; 95 \%$ confidence intervals $=1.059-4.152,6.220-37.079$, and 1.016-3.540; $p=0.033,<0.001$, and 0.044 , respectively).

\section{Discussion}

Previous studies characterised $m i R-7$ as a tumour-suppressor gene in several types of cancer, including melanoma (11) and breast cancer (12). In those studies, $m i R-7$ was shown to reduce the expression of several oncogenes, such as epidermal growth factor receptor (14), p21-activated kinase 1 (15), and others (16).

In contrast, some lines of evidence revealed that $m i R-7$ has an oncogenic role. Yu and colleagues used quantitative real-time PCR to show that $m i R-7$ was significantly upregulated in 48 renal cell carcinoma tissues compared to paired normal tissues. They also revealed that the inhibition of $m i R-7$ expression suppressed migration, proliferation, and anti-apoptosis in a series of in vitro experiments (17). Another study found that serum $m i R-7$ was significantly increased in patients with epithelial ovarian cancer (EOC) compared with healthy women. Levels of circulating $m i R-7$ were found to be significantly increased in patients with lymph node metastases and International Federation of Gynecology and Obstetrics stage III-IV EOC. Furthermore, $m i R-7$ overexpression induced migration and invasion in an ovarian cancer cell line, while $m i R-7$ inhibition suppressed the migration of EOC cell lines, indicating the oncogenic function of $m i R-7$ and diagnostic potential of circulating $m i R-7$ up-regulation in patients with advanced EOC (18).

In the field of CRC research, a recent study reported increased miR-7 expression in both tissue and faecal specimens from patients with colon cancer (15). Another group showed that $m i R-7$ was gradually increasingly overexpressed with each subsequent step of carcinogenesis, from low-grade dysplasia to advanced CRC. Moreover, the transfection of human colon cancer DLD-1 cells with anti-miR-7 suppressed proliferation, suggesting that $m i R-7$ might function as an oncogenic role in CRC (14). Consistent with these findings, our current study also demonstrated that $m i R-7$ expression levels were higher in CRC tissues compared with normal mucosae, especially in advanced cancer. To the best of our knowledge, the clinical impact of miR-7 expression in CRC tissues has not been assessed. Therefore, a major finding of our study was that the overexpression of $m i R-7$ in CRC tissues is significantly correlated with clinicopathological factors, indicating that $m i R$ 7 might be closely involved in CRC progression.

Another important finding of our study is the prognostic impact of miR-7 expression in CRC. Little is known about the use of $m i R-7$ expression as a prognostic marker, and only one study to our knowledge has investigated the association between miR-7 expression and prognosis in CRC. In this previous study, Yang et al. showed that $m i R-7$ expression was considerably higher in samples from patients with early relapse compared with those from non-early relapse, indicating that an early relapse is significantly associated with increased $m i R-7$ expression. They also demonstrated that patients in the high $m i R-7$ expression subgroup had significantly worse disease-free survival and overall survival times than those in the low $m i R-7$ expression subgroup (19). However, these data included only 104 patients with primary CRC stages II-III (54 patients with non-early relapse and 50 with early relapse after radical resection), and the authors noted the need for a large-scale study. Our study evaluated all patients (stages 0-IV), and demonstrated that those with high $m i R-7$ expression had a significantly poorer prognosis compared with those with low miR-7 expression in this cohort $(p=0.010)$. We also identified tissue $m i R-7$ expression as one of the independent predictors of poor overall survival in patients with CRC.

In conclusion, we found that $m i R-7$ expression levels were significantly higher in CRC tissues than in normal mucosae, and that high expression levels were significantly associated with the malignant potential of CRC and poor prognosis in patients with CRC. This suggests that the assessment of $m i R$ 7 expression in primary tissues could be used as a clinically feasible prognostic biomarker to realise personalized treatment, and might help predict clinical outcomes and improve prognosis of patients with CRC.

\section{Funding}

This work was supported in part by Grants-in Aid for Scientific Research (no. 26293301, and 15K10134) from the Ministry of Education, Culture, Sports, Science, and Technology, Japan.

\section{References}

1 Torre LA, Bray F, Siegel RL, Ferlay J, Lortet-Tieulent J and Jemal A: Global Cancer Statistics: 2012. CA Cancer J Clin 65: 87-108, 2015

2 Center MM, Jemal A and Ward E: International trends in colorectal cancer incidence rates: Cancer Epidemiol. Biomarkers Prev 18: 1688-1694, 2009.

3 Andre N and Schmiegel W: Chemoradiotherapy for colorectal cancer. Gut 54: 1194-1202, 2005.

4 Lurje G, Zhang W and Lenz HJ: Molecular prognostic markers in locally advanced colon cancer. Clin Colorectal Cancer 6: 683690, 2007.

5 Felekkis K, Touvana E, Stefanou Ch and Deltas C: MicroRNAs: A newly described class of encoded molecules that play a role in health and disease: Hippokratia 14: 236-240, 2010.

6 Winter J, Jung S, Keller S, Gregory RI and Diederichs S: Many roads to maturity: microRNA biogenesis pathways and their regulation. Nat Cell Biol 11: 228-234, 2009.

$7 \mathrm{Ha} \mathrm{M}$ and Kim VN: Regulation of microRNA biogenesis. Nat Rev Mol Cell Biol 15: 509-524, 2014. 
8 Cortez MA and Calin GA: MicroRNA identification in plasma and serum: a new tool to diagnose and monitor diseases. Expert Opin Biol Ther 9: 703-711, 2009.

9 Faruq O and Vecchione A: microRNA: Diagnostic Perspective. Front Med 2: 51, 2015.

10 Toiyama Y, Tanaka K, Inoue Y, Mohri Y and Kusunoki M: Circulating cell-free microRNAs as biomarkers for colorectal cancer. Surg Today 46: 13-24, 2016.

11 Giles KM, Brown RA, Epis MR, Kalinowski FC and Leedman PJ: miRNA-7-5p inhibits melanoma cell migration and invasion. Biochem Biophys Res Commun 430: 706-710, 2013.

12 Shi Y, Luo X, Li P, Tan J, Wang X, Xiang T and Ren G: miR-7$5 p$ suppresses cell proliferation and induces apoptosis of breast cancer cells mainly by targeting REG $\gamma$. Cancer Lett 358: 27-36, 2015.

13 Chen WQ, Hu L, Chen GX and Deng HX: Role of microRNA7 in digestive system malignancy. World J Gastrointest Oncol 8: $121,2016$.

14 Nakagawa Y, Akao Y, Taniguchi K, Kamatani A, Tahara T, Kamano T, Nakano N, Komura N, Ikuno H, Ohmori T, Jodai Y, Miyata M, Nagasaka M, Shibata T, Ohmiya N and Hirata I: Relationship between expression of onco-related miRNAs and the endoscopic appearance of colorectal tumors. Int J Mol Sci 16: 1526-1543, 2015.

15 Ahmed FE, Ahmed NC, Vos PW, Bonnerup C, Atkins JN, Casey M, Nuovo GJ, Naziri W, Wiley JE, Mota H and Allison RR: Diagnostic microRNA markers to screen for sporadic human colon cancer in stool. I. Proof of principle: Cancer Genomics Proteomics 10: 93-113, 2013.
16 Sobin L and Gospodarowicz MW C: TNM Classification of Malignant Tumors, Seventh Edition: Wiley, 2009.

17 Yu Z, Ni L, Chen D, Zhang Q, Su Z, Wang Y, Yu W, Wu X, Ye $\mathrm{J}$, Yang S, Lai Y and Li X: Identification of $m i R-7$ as an oncogene in renal cell carcinoma. J Mol Histol 44: 669-677, 2013.

18 Meng X, Joosse SA, Müller V, Trillsch F, Milde-Langosch K, Mahner S, Geffken M, Pantel $\mathrm{K}$ and Schwarzenbach $\mathrm{H}$ : Diagnostic and prognostic potential of serum $m i R-7, m i R-16$, $m i R-25, m i R-93, m i R-182, m i R-376 a$ and $m i R-429$ in ovarian cancer patients. Br J Cancer 113: 1358-1366, 2015.

19 Yang IP, Tsai HL, Miao ZF, Huang CW, Kuo CH, Wu JY, Wang WM, Juo SH and Wang JY: Development of a deregulating microRNA panel for the detection of early relapse in postoperative colorectal cancer patients. J Transl Med 14: 108, 2016.
Received September 30, 2016

Revised October 13, 2016

Accepted October 14, 2016 